\title{
A Psicologia Política das Classes Sociais no Brasil: Atributos das Atitudes Políticas por Estratificação e Mobilidade Social
}

\author{
Lucio Rennó ${ }^{1}$ \\ Mathieu Turgeon ${ }^{1}$ \\ 1. Universidade de Brasília (UnB). Brasília, DF, Brasil. E-mail de contato: luciorenno@unb.br.
}

\section{INTRODUÇÃO}

$\mathrm{O}$ Brasil contemporâneo é testemunha de um processo acelerado de mudanças estruturais e político-institucionais concomitantes que tem resultado na mais profunda (e não antecipada) dinâmica de incorporação de massas à economia de mercado e ao sistema político democrático. Trinta anos atrás, a possibilidade de erradicação da miséria no país e redução da pobreza e desigualdade era utopia. Mobilidade social ascendente era vista como limitada e improvável. O Brasil da década de 1980 e início da de 1990 era um país completamente distinto daquele em que vivemos hoje. O consumo era restrito a pequenas parcelas da população, a renda era concentrada e a exclusão social e política era predominante. Embora em 2015 o país tenha experimentado piora dos indicadores econômicos e acirramento da disputa política em relação à data de coleta dos dados para este trabalho (2012), a situação hoje é ainda bastante distinta das décadas passadas.

Por outro lado, os gargalos estruturais ainda são muito presentes e preocupantes. Hospitais e escolas públicas continuam precários. A desigualdade de acesso ao ensino público superior gratuito permanece gritante. A qualidade de vida nos centros urbanos, marcada por problemas graves de mobilidade urbana e pela violência e falta de se-

DADOS - Revista de Ciências Sociais, Rio de Janeiro, vol. 59, n- 1, 2016, pp. 11 a 51. 
gurança pública continua preocupante. As manifestações de junho de 2013 não deixam dúvidas de que, a despeito dos avanços sociais e econômicos vividos nas últimas décadas, a insatisfação com os serviços públicos apenas aumenta. Aparentemente, a maior capacidade de consumo de setores antes excluídos não é acompanhada por uma melhora dos serviços públicos aos quais esses mesmos setores estão destinados. Se a situação das famílias melhorou para dentro da casa, com mais acesso ao consumo, o mesmo não pode ser dito quanto à realidade de fora da casa, no que tange ao acesso a serviços públicos de qualidade.

De fato, a conjunção desses processos trouxe para o centro do debate sobre comportamento político os potenciais efeitos do surgimento de uma nova classe média e as implicações políticas das mudanças socioeconômicas nas percepções política e social da população brasileira (Souza e Lamounier, 2010; Souza, 2012; Braga, 2012; Singer, 2012). A literatura internacional sobre classes sociais e comportamento político tem larga tradição em explorar como setores intermediários de uma sociedade e a mobilidade social têm efeitos positivos na moderação de conflitos sociais e aumento da tolerância política. Em particular, associa-se às classes médias e ascendentes uma postura mais aberta, tolerante e moderada. Podemos esperar o mesmo da estrutura de classes no Brasil?

Recorrer a conceitos centrais da psicologia política para entendermos como estratificação e mobilidade social afetam as atitudes políticas e seus atributos pode ser uma saída interessante. Atitudes como tolerância certamente devem ser investigadas, mas também as características das próprias atitudes políticas, como sua rigidez ou flexibilidade, moderação ou radicalidade nos ajudam a entender o perfil atitudinal da população brasileira. Para tanto, nos remetemos à literatura sobre psicologia política (Kuklinski, 2002). Inovamos, portanto, ao estudar os atributos das atitudes políticas como indicadores de moderação, flexibilidade e heterogeneidade das opiniões das distintas classes sociais. De fato, esses elementos são apontados pela literatura clássica sobre classes sociais como componentes de seu perfil atitudinal.

Assim, podemos esperar que a classe média tenha atitudes mais moderadas, flexíveis (menos cristalizadas) e diversificadas do que outros grupos sociais? Grupos vivenciando processos de mobilidade social, por sua vez, dada sua experiência de vida, poderiam ter atitudes menos extremadas e rígidas? Parte da literatura sobre classes sociais e po- 
lítica nos levaria a crer que sim e que isso seria positivo para o funcionamento da democracia.

Por outro lado, como podemos tecnicamente caracterizar esses atributos das atitudes políticas? Investigaremos se as opiniões das diferentes classes sociais são cristalizadas ou se as pessoas não têm opiniões formadas sobre certos temas. Essa é a discussão sobre não opinião e opinionation, raramente trabalhada no Brasil ${ }^{1}$. Opiniões cristalizadas, definidas, podem representar menos flexibilidade para adequar as atitudes a novos cenários e mudanças. Também cabe perguntar se as opiniões existentes são extremadas ou moderadas; se há classes sociais cujas atitudes sejam menos radicais e, portanto, mais abertas e afeitas ao debate e ao convencimento. Por último, é interessante verificar o grau de heterogeneidade de opiniões internas a uma classe social específica. Isso indicaria se, de fato, podemos mesmo falar de compartilhamento de atitudes em uma mesma classe ou se sua variação interna é tão acentuada que impossibilita uma identidade comum.

Cabe salientar que examinaremos tanto a estratificação social (divisão em classes sociais), quanto a mobilidade social (mudança de classe social). Dessa forma, seguimos o trabalho de Peixoto e Rennó (2011) que aponta para a importância da mobilidade social no voto em Dilma Rousseff nas eleições de 2010.

Por último, é fundamental introduzir no debate sobre classes sociais no Brasil a literatura crítica aos efeitos da estratificação social nas opiniões individuais. Essa literatura aponta para uma semelhança crescente entre classes sociais, dado o acesso a fontes semelhantes de informação e experiências vividas. Ou seja, as opiniões na sociedade tornam-se cada vez mais parecidas, a despeito de trajetórias de vida distintas. De certa forma, estaríamos testemunhando a morte gradual das subculturas políticas e a predominância de visões majoritárias na opinião pública.

Na próxima seção discutiremos os princípios teóricos que orientam nossa análise, derivando hipóteses embasadas em nosso debate sobre a psicologia política das classes sociais. Em seguida, testaremos as hipóteses usando dados do Barômetro das Américas, rodada de 2012. Por fim, faremos ilações acerca dos atributos das atitudes de classe no Brasil. 


\section{ESTRATIFICAÇÃO SOCIAL, MOBILIDADE SOCIAL E ATITUDES POLÍTICAS}

O debate sobre classes sociais é central no estudo da economia política. Podemos pensar em, ao menos, quatro correntes de pesquisa: abordagens histórico-institucionais sobre as bases sociais e econômicas dos regimes políticos (Moore, 1983; Acemoglu e Robinson, 2006; Boix, 2003); a teoria da modernização e suas implicações para o comportamento político (Lipset, 1959); estudos mais recentes que empiricamente avaliam o efeito (ou ausência deste) da estratificação social em diversos indicadores de comportamento político (Krieckhaus et al., 2014); e o debate contemporâneo sobre a nova classe média no Brasil e na América Latina (Neri, 2010; Souza e Lamounier, 2010; Souza, 2012; Braga, 2012; Singer, 2012; Ferreira et al., 2013). Com base nessas teorias, delinearemos hipóteses sobre como membros das diferentes classes sociais pensam sobre a política, traduzindo-as em conceitos da psicologia política.

O estudo de Barrington Moore (1983) oferece uma explicação para os processos de formação de regimes políticos no mundo moderno embasado na disputa distributiva entre classes sociais que vivenciam processos de mobilidade social. Uma parte central dessa análise é a ênfase nas mudanças dos valores e atitudes de classes sociais como estopim para processos mais profundos de alteração da ordem institucional. $\mathrm{O}$ exemplo paradigmático são os yeoman na Inglaterra e seu ímpeto inovador através dos enclosures, que nada mais são do que invasões de terra coletivas. É daí que surge a ideia de propriedade privada e a necessidade de sua defesa e regulamentação.

Obviamente, tal processo não se dá sem conflito. No caso supracitado, havia a diferença de atitudes e crenças em relação a outros grupos, ou classes sociais, como os camponeses, que se agarravam a valores mais tradicionais e resistiam às mudanças. Assim, a fricção interclasse passa a ser fundamental para entender processos de mudança e continuidade política. Cabe destacar na argumentação de Moore (1983) a fragilidade do governo central inglês como elemento que propiciou o dinamismo das inovações encabeçadas por grupos sociais. Essa dinâmica culmina, posteriormente, na predominância das preferências desses setores sobre que quadro institucional adotar. No caso da Inglaterra, a opção foi o parlamentarismo democrático².

Nos pontos citados, prevalece a centralidade da mobilidade social. Mas, a própria estratificação social também tem peso na explicação de 
Moore (idem). Outra classe social importante, o gentry, aristocracia rural acima dos yeoman e abaixo da nobreza, desempenhou papel central na definição dos rumos políticos e históricos da Inglaterra. O gentry serviu de buffer class, uma espécie de classe tampão, permitindo negociações entre os setores insatisfeitos e dando apoio à visão de inovação que resultou na decapitação do rei Carlos I e no fim das restrições absolutistas aos enclosures. Esse grupo, por ser intermediário, entendia o problema pelos dois ângulos e estava aberto à discussão, com preferências mais maleáveis (menos cristalizadas) e moderadas. Isso abriu espaço institucional para a consolidação da nova ordem, tanto na economia quanto na política, que passou a ser regida pelo Parlamento, algo que na época se assemelhava a uma comissão de senhores rurais (Moore, 1983:27). A maior parte da população da Inglaterra (campesinato e assalariados urbanos e rurais) continuou excluída do processo decisório na nova ordem. Reafirma-se, assim, a inclusão seletiva oriunda de processos concomitantes de mobilidade social ascendente de certos setores e o papel de intermediário de grupos já consolidados, permitindo avanços setoriais e "controlados" às expensas de uma inclusão generalizada, universal, via revolução. Venceu uma aliança que combinava preferências pela democracia parlamentarista e pelo capitalismo. Os enclosures são legalizados pelo Parlamento, cada vez mais populado por yeoman e gentry. Ou seja, a reconstrução da ordem política tem bases sociais.

Acemoglu e Robinson (2006) adotam argumento semelhante, dando maior ênfase à classe média como grupo tampão. Para esses autores, as classes médias são elementos de estabilidade da democracia por serem moderadas e por terem uma postura política progressista, intermediando demandas radicais ao mesmo tempo em que obtêm avanços de inclusão social e política e limitação do poder da elite, tendo papel semelhante ao gentry na Inglaterra descrita por Moore. Ao agir como um amortecedor do conflito redistributivo entre ricos e pobres, a classe média atenua pressões por redistribuição e, ao fazer isso, reduz os riscos de reações repressivas das elites. A classe média, assim, adota postura moderada, propícia para o fortalecimento de regimes democráticos, arrefecendo o conflito entre demandas radicais por redistribuição pró-pobre e o desejo de repressão das demandas redistributivas por parte das classes altas. A equação é simples para Acemoglu e Robinson (idem): quanto maior o setor intermediário na estrutura de classes, menos conflito social. 
Dessa forma, para a abordagem que enfatiza as bases sociais e econômicas da democracia, a mobilidade social enseja inovação institucional. Já a estratificação social, via setores intermediários na sociedade, modera e atenua conflitos que poderiam resultar em perdas coletivas. São interesses econômicos e de sobrevivência política que guiam a ação das classes sociais e seus representantes políticos, afetando reformas institucionais com o propósito explícito de controlar os desdobramentos do conflito social no futuro. Em parte, a ação de classes sociais médias na discussão acima é de moderar o conflito redistributivo, com uma proposta de inclusão seletiva e gradual, sem correr riscos de exacerbar a repressão potencial das classes altas.

A discussão sobre classes sociais e política obviamente tem na Teoria da Modernização outro grande pilar. Seymour Martin Lipset é um dos primeiros a articular desenvolvimento econômico e valores democráticos, referindo-se especificamente aos efeitos da modernização econômica nos valores políticos. Em seu clássico trabalho "Some Social Requisites of Democracy: Economic Development and Political Legitimacy" (1959), argumenta que o desenvolvimento econômico, quando propicia maior acesso a informação, educação e renda, é fundamental para permitir que as classes baixas expandam seus horizontes temporais, complexifiquem suas visões sobre política e adotem uma postura mais gradualista, reformista e não revolucionária do processo político. A exposição a pontos de vista discordantes modera as classes intermediárias, reduz a intensidade dos comprometimentos a uma ideologia única e amplifica a moderação. Assim, processos de mudança estrutural na economia, com combate à pobreza e desigualdade, não só incorporam economicamente setores excluídos, mas os aproximam da comunidade política nacional e os distanciam de propostas sectárias. Dessa forma, modernização econômica engendra incorporação valorativa: torna as classes baixas mais parecidas com as classes médias e seus valores (Lipset, 1959:83). É interessante notar que esse processo, portanto, atenua também diferenças entre classes sociais.

Sobre a classe média em particular, Lipset argumenta que "uma grande classe média desempenha um papel mitigador na moderação de conflitos uma vez que é capaz de premiar partidos moderados e democráticos e penalizar grupos extremistas" (idem; tradução livre) ${ }^{3}$. Para o autor, claramente são os atributos das atitudes das classes intermediárias e sua tolerância que definem a dinâmica do conflito político. Mo- 
deração atitudinal e tolerância são elementos definidores da classe média e de sua significativa contribuição para uma democracia pluralista.

Modernização política e desenvolvimento econômico (com propensão mais igualitária, caberia acrescentar) também reduzem a tendência dos mais ricos e poderosos se sentirem ameaçados caso deixem o poder, permitindo alternância. Onde todos são mais iguais economicamente, as pressões redistributivas que ameaçam os ricos são menores, assim como as reações contrárias à redistribuição (ibidem:84). Nessa visão, democracias sobrevivem em Estados com moderados níveis de conflito. Rivalidades profundas e irreconciliáveis entre classes, etnias, partidos, ideologias e outras clivagens reduzem a possibilidade de formação de consensos básicos de apoio e legitimidade do regime, mesmo em situações de baixa eficiência governamental (ibidem:92). Assim, o crescimento de sociedades em formato de diamante (classes intermediárias prevalecendo) ao invés de piramidal (classes baixas prevalecendo) resulta em maior legitimidade e apresenta também maior eficiência: tornam-se sistemas políticos democráticos mais estáveis.

Em suma, na visão da Teoria da Modernização, segundo um de seus principais pontífices, conflito político moderado, que permite a construção de caminhos e valores compartilhados, tolerando dissenso, é o cenário ideal para a estabilidade da democracia. Esse conjunto de valores é marcado por uma sociedade composta predominantemente por uma classe que é heterogênea e diversa, respeita e tolera o diferente e está exposta a uma pletora de fontes de informação, de visões de mundo e de preferências. Ou seja, é importante um corte transversal das atitudes políticas pelos estratos sociais e que não sejam particulares a um ou outro: é fundamental que haja diversidade de exposição a ideias políticas e que haja valores cruzados entre grupos sociais (ibidem:97). As classes médias são mais propensas a apresentar esses traços atitudinais. Assim, elas seriam mais tolerantes, mais abertas a novas ideias e mais heterogêneas em seus valores que outras classes.

É fundamental destacar que, no extremo, a visão lipsetiana aponta para um caminho de erradicação das clivagens sociais e políticas. De forma inesperada, essa visão consubstancia a perspectiva dominante de uma geração mais recente de pesquisas céticas quanto ao poder explicativo da estratificação e mobilidade social. Esse grupo advoga não haver qualquer influência das classes sociais no comportamento político. No caso, a heterogeneidade valorativa apontada por Lipset passa 
a negar a diferenciação de classe como fator explicativo do comportamento político. Passam a ser relevantes as redes sociais, formadas onde moram, trabalham e se encontram as pessoas, definindo as visões de mundo e opiniões individuais. Assim, a ideia de classe só se torna real quando marcada pelo convívio cotidiano de seus membros. Em não havendo tal convívio, ou sendo este múltiplo, inserido em redes diversas, expostas a fontes variadas de informação, o compartilhamento de experiências de vida, presumido na ideia de classe, deixa de existir. Assim sendo, as classes sociais seriam heterogêneas demais para apresentar valores compartilhados ou semelhantes demais em compartilhar visões de mundo parecidas, o que impediria sua diferenciação. Consequentemente, clivagens de classe não teriam efeito na constituição das preferências individuais (Butler e Stokes, 1974; Kelley e McAllister, 1985; Langton e Rapoport, 1975; Huckfeldt e Sprague, 1995).

Portanto, a hipótese que emerge desse último grupo de estudos é a ausência de relevância política das classes sociais, pois estas não distinguiriam indivíduos, a não ser em circunstâncias muito específicas. Prevaleceria a hipótese nula, de que não há efeito da estratificação social no comportamento político.

Após essa onda de descrença e um arrefecimento da discussão sobre estratificação e mobilidade social no estudo da política, há um interesse renovado pela ideia de classe social, sobretudo na América Latina. A conjunção de: a) governos de esquerda; b) ganhos de renda; c) inclusão no mercado interno; e d) politização de um dito conflito de classes (Handlin, 2013) trouxe a discussão sobre estratificação e mobilidade de volta ao centro do estudo sobre comportamento político.

No Brasil, esse debate tem ganhado visibilidade porque houve, como apontam pesquisas recentes (Neri, 2010), avanços relevantes na redução da desigualdade e pobreza no país. Esses ganhos estruturais têm gerado um padrão de mobilidade social ascendente. Os ganhos em capacidade de consumo, aumento da renda e escolaridade têm sido empiricamente verificados. Esse processo afeta a forma como as pessoas pensam sobre política, e com isso passou a ser preocupação central de pesquisadores, políticos e governo. Afinal, esse novo grupo, novo porque sofreu mobilidade social e alcançou patamares de renda e consumo típicos de uma classe média emergente, pode se tornar decisivo para pensarmos o futuro não tão distante do país. Alguns textos têm se 
debruçado sobre a questão. Vamos explorá-los, em ordem cronológica, para revisarmos o que já sabemos sobre a questão no Brasil.

Souza e Lamounier (2010) apresentam uma visão inicial pessimista sobre a nova classe média brasileira, argumentando que o perfil atitudinal desse grupo é marcado pela tolerância às transgressões que marcam a política brasileira do passado e do presente. A pergunta que colocam é se a nova classe média brasileira é um ator de mudança da herança patrimonialista ou não. Seus estudos, baseados em pesquisas de opinião, apontam que há relação entre classe e visões sobre crise moral e transgressões: classes mais abastadas veem problemas dessa natureza como piores, e essa percepção cai na medida em que se move para classes mais baixas. Dessa forma, os achados de Souza e Lamounier vão ao encontro de estudo anterior de Alberto Almeida (2007) sobre a cabeça do brasileiro, que embora enfoque o efeito da escolaridade, e não o da estratificação social, também chega a conclusões semelhantes. Não é injusto dizer que, para esses autores, o melhor do Brasil são as elites.

Em ambos os estudos, cabe ressaltar, há um possível viés de aceitabilidade social, muito associado a níveis educacionais, guiando as respostas dadas pelos entrevistados às perguntas das pesquisas de opinião (Fowler, 1995). Os letrados têm mais conhecimento para discernirem que devem mascarar suas verdadeiras opiniões e responder às questões segundo suas crenças do que é socialmente desejável, do que é politicamente correto. Assim, a aceitação de práticas oportunistas, confusão entre público e privado, jeitinho e corrupção seriam apenas melhor mascaradas por alguns do que por outros, dado justamente seu nível educacional. Trata-se, portanto, de sério problema de endogeneidade, quando se confunde a direção da causalidade entre vetores explicativos e de resultado.

Outro ponto de Souza e Lamounier é que a confiança interpessoal, como indicador de capital social, é bastante menor em classes mais baixas (2010:106). A participação em organizações da sociedade civil também é menor nesses grupos. Contudo, ressaltam que a participação religiosa nas classes mais baixas "fornece parâmetros significativos de sociabilidade" (ibidem:118). Assim, a participação religiosa das pessoas passa a ser fundamental para entendermos algum mecanismo de construção de capital social dos mais pobres, mesmo que incipiente. 
Dessa forma, prevalece na visão de Souza e Lamounier uma postura pessimista acerca do papel político da nova classe média. Todavia, além da limitação causada pela aceitabilidade social, o que se enfoca nessa abordagem é a estratificação social, e não a mobilidade social. Esses autores falam de nova classe média, mas a operacionalizam com um indicador estático de estratificação social em que a dita "nova" classe social é codificada como a classe média-baixa em seu questionário. Não há, portanto, qualquer indicador de mudança de classes que esteja explícito no qualificador "nova". Supor que a classe médiabaixa é composta por novos setores ascendentes é uma hipótese a ser testada e não um pressuposto válido.

Em visão contrária (embora que padeça também do último problema citado), Jessé Souza define a nova classe média como os batalhadores, um grupo de pessoas que acredita no trabalho e se dedica de forma esforçada e convicta a conquistar uma vida melhor através do esforço pessoal. São a religião e a família que sedimentam a crença de que com dedicação, sacrifício e sofrimento se consegue avançar na vida. Usando trajetórias de vida e entrevistas aprofundadas como metodologia preferencial, Souza e seus colaboradores desvendam a relação entre essas variáveis na cabeça dos entrevistados. A junção entre religião, família, sofrimento e trabalho gera uma visão de mundo compartilhada, uma experiência parecida entre pessoas mesmo que estas tenham trajetórias de vida distintas e não convivam. Essa visão de mundo compartilhada surge da vivência de experiências semelhantes, ainda que geograficamente distantes. Dessa maneira, não é o convívio que define a classe, mas passar por situações semelhantes de vida como a escassez de alimentos, o subemprego, a devoção religiosa e assim por diante.

Para Souza, tais visões de mundo têm implicações políticas que se refletem no dito "lulismo". Nesse caso, o lulismo não é amorfo ou resultado de um bom governo, mas "representa uma manifestação dos conteúdos cognitivos, morais e estéticos incorporados no ethos do trabalho e na racionalização de uma ética do sofrimento" (2012:251). Segundo Souza, Luiz Inácio Lula da Silva encarna essa mesma ética e passa a ser visto como um batalhador que obteve sucesso e trilhou caminhos parecidos, em suas linhas gerais, aos de boa parte das pessoas que tiveram ascensão social nos últimos anos. Lula da Silva exemplifica a vida desse grupo, o que gera simpatia e adesão a seu projeto político de combate à injustiça social através da redistribuição de renda pelo Estado. 
Contudo, causa estranheza nessa análise a ausência de referências e citações explícitas a afirmações de entrevistados e de populares sobre o lulismo. Em outras passagens do livro de Jessé Souza, extensos relatos das histórias de vida e das falas dos entrevistados são citados, o que enriquece enormemente o estudo. Em sua breve discussão sobre as visões políticas dos batalhadores, não há sequer uma referência empírica direta à fala ou interpretação dada à realidade de alguma pessoa além daquela que aparentemente é do próprio autor. Assim, pairam dúvidas se as ideias expressas por Souza são suas interpretações livres do mundo ou se são, de fato, afirmadas pelos sujeitos analisados no livro. Passa a ser difícil diferenciar na avaliação desse autor suas próprias crenças e opiniões pessoais daquelas expressas por seus entrevistados, levantando questionamentos sobre a objetividade de sua análise, entendida como validação interpares das afirmações feitas.

Por último, cabe destacar que no livro de Souza não há qualquer parâmetro comparativo dos batalhadores com outros grupos. Assim, não sabemos se aquelas visões de mundo são particulares àquela classe social ou não.

Na mesma linha de Souza, André Singer se propõe a pensar o conteúdo substantivo da ideologia que embasa o lulismo $(2009,2012)$. Lulismo, para Singer, combina demandas por ordem e justiça social, incorporando à base de apoio popular de Lula da Silva as camadas mais pobres da sociedade (classes E e D), que apresentam inclinações tanto conservadoras quanto progressistas. Desse modo, o voto de Lula da Silva deixa de ser marcado por uma ideologia clara de esquerda, o que ocorria até 2002, e incorpora grupos sociais que antes votavam na direita. Isso ocorre porque Lula da Silva fez um ótimo governo, com indicadores econômicos e sociais bastante positivos, mas também porque moderou seu discurso e criou vínculos de caráter pessoal, marcados por um passado compartilhado, o que facilitou uma comunicação direta com o eleitor pobre.

Para Singer, a disputa de classes que se coloca é de uma classe média orientada pela preocupação com a corrupção e grupos mais pobres, que olham para a redistribuição de renda como meta (2012:15). Esses grupos mais pobres foram os maiores beneficiados por processos de mobilidade social. O lulismo é uma posição ideológica que diferencia pobres e ricos e não mais esquerda e direita (ibidem:32), e passa a ser a ideologia política dos pobres que vivenciaram acelerada mobilidade 
social nos dois mandatos de Lula da Silva. Dessa maneira, Souza e Singer adotam visão bastante semelhante sobre esses setores.

Também como o caso de Souza (2012), os dados que comprovam essas afirmações rareiam na análise de Singer (2012). Estas são embasadas em pesquisas de opinião pública, essencialmente descritivas (também como as de Souza e Lamounier, 2010) e não apresentam testes de significância estatística para diferenciar opiniões entre classes sociais. Tampouco é dito algo sobre os que vivenciaram processos de mobilidade social. Diferentemente de Souza e Lamounier, o leque de dados analisados por Singer é bem mais modesto, o que nos dá uma ideia ainda mais limitada sobre o fenômeno das preferências políticas da nova classe média.

Além das questões metodológicas, a literatura citada, sobretudo a brasileira, ignora por completo os elementos que caracterizam os atributos das atitudes políticas das diferentes classes sociais - uma psicologia política de classes - e dos que vivenciaram processos de mobilidade social.

Em particular, pretendemos explorar aspectos associados à tolerância política das classes sociais. A tolerância pode se exprimir substantivamente, dizendo o que ou quem se tolera, mas pode também ser evidenciada de forma mais subliminar, pelos atributos das características das atitudes políticas. O estudo da psicologia política, que enfoca exatamente o entendimento de como atitudes se constroem, se consolidam e mudam, ou seja, as características das atitudes para além de seus significados substantivos passa a ser fundamental para melhor definirmos como pensa a classe média brasileira.

\section{PARA UMA PSICOLOGIA POLÍTICA DA ESTRATIFICAÇÃO E MOBILIDADE SOCIAL}

Em primeiro lugar, é preciso tratar a questão da ausência de opinião, ou seja, a não opinião (Krosnick e Milburn, 1990). Esse fenômeno é indicado pela inexistência de posicionamento ou atitude de um cidadão acerca de certo tema. Podemos, simplesmente, não ter uma posição definida sobre algum assunto.

Sabemos que a não opinião é mais frequente entre certos grupos da sociedade, em parte entre os de baixa renda e educação (Schuman e Presser, 1981). A maior frequência da não opinião entre alguns grupos 
representa um problema importante para o processo democrático porque a opinião pública como um todo acaba sobrerrepresentando (e então sub-representando) as opiniões de alguns grupos. Estudos conduzidos nos Estados Unidos, por exemplo, mostram que os pobres, os jovens, os menos educados, as mulheres e os negros não têm opiniões formadas sobre vários assuntos políticos quando comparados com os mais ricos, os mais educados, os homens e os brancos (Bishop, Tuchfarber e Oldendick, 1986; Schuman e Presser, 1981). Rennó (2007) já apontou que há diferenças importantes na não opinião por renda e escolaridade no Brasil, o que pode distorcer a representação dos interesses desses grupos. Nessa visão, a não opinião é um problema que resulta em grande medida da distribuição desigual da informação política pela sociedade (Althaus, 1996; Krosnick e Milburn, 1990; Delli Carpini e Keeter, 1994; Luskin, 1990).

Por outro lado, a não opinião pode também ser sinal de abertura, de potencial predisposição à incorporação de novos conceitos. Opiniões cristalizadas, por sua vez, dão menos margem a ambiguidades, mas também demonstram menor predisposição ao novo e a julgamentos mais ponderados, que buscam um distanciamento acerca do tema-alvo da opinião (Conner e Armitage, 2008). Quando pensamos na discussão sobre ambivalência atitudinal, nela fica claro que o processamento de informações é afetado pelo grau de não atitude dos cidadãos. Eleitores mais convencidos e seguros de uma ideia acabam por mais comumente enviesar o uso da informação para fortalecer suas opiniões e atitudes, o que chamamos de "raciocínio motivado" (Kunda, 1990; Redlawsk, 2002). Dessa forma, eleitores com visões mais cristalizadas tendem a dar mais ênfase a informações positivas, selecionando propositalmente as informações que usam, visando confirmação de suas atitudes enraizadas sobre certo objeto (candidato ou partido, por exemplo). Por outro lado, maior incerteza e/ou ambiguidade, gera maior ênfase em novas informações, que estimulariam uma correção da atitude ou posição adotada pelo eleitor (Thornton, 2011).

Assim, eleitores que não têm atitudes fixas - e a não opinião é aqui entendida como um indicador disso - poderiam processar informações negativas e positivas sobre um tema de forma equilibrada, pesando quais são mais convincentes e usando-as para definir sua posição. A literatura sobre ambivalência atitudinal, introduzida no estudo do comportamento eleitoral brasileiro por Rennó e Ames (2014), indica que não ter opinião firme sobre algo pode ser resultado de conflitos valora- 
tivos no indivíduo, e isso levaria a compromissos atitudinais menos rígidos. Eleitores com atitudes mais flexíveis, menos cristalizadas, seriam menos enviesados por suas crenças anteriores. Por gerar menos confiança, firmeza em uma atitude, ambivalência passa a ser um estímulo a buscar mais informação (abertura informacional) e a mais sistematicamente processá-la. Nesse caso, não respostas, não ter opinião acerca de um tema, pode indicar abertura para novas informações e tolerância acerca de posições contrárias e contraditórias ${ }^{4}$. Seria, assim, um atributo positivo das atitudes de uma possível nova classe média.

Dadas as expectativas teóricas contraditórias a respeito da não opinião, a questão se mostra aberta a verificação empírica. Se as opiniões forem linearmente ordenadas por classe, decrescendo a não opinião na medida em que a classe social sobe de baixa a alta, então temos um indício de que a não opinião é atribuída a problemas de distribuição desigual de informações, beneficiando ricos e prejudicando pobres. Por outro lado, se ela for específica a uma classe, isso indica sua particularidade e possível maior flexibilidade atitudinal.

Mas a não opinião é apenas uma das características das atitudes que nos interessa. Também investigamos a força das atitudes. É concebível pensar que algumas classes, por terem seus interesses melhor definidos, tendem a possuir opiniões políticas que sejam mais extremas. Esse "extremismo" nas opiniões políticas pode ter consequências importantes para uma sociedade, limitando ou reduzindo o espaço para o diálogo entre as classes, aumentando a friçcão interclasse e colocando entraves ao bom funcionamento da democracia ${ }^{5}$.

Opiniões extremas geram tensões ainda maiores em uma sociedade quando tendem a se agrupar em polos opostos, longe do meio. Esse é o fenômeno de uma opinião pública polarizada. Nessa situação, os interesses e as preferências políticas de alguns grupos da sociedade encontram-se na posição diametralmente oposta aos interesses e às preferências políticas de outros. Porém, o que atenuaria a polarização das opiniões políticas numa sociedade seria a presença de uma classe intermediária (buffer) volumosa e com percepções políticas heterogêneas. Moore, Acemoglu e Robinson e também Lipset já apontavam para esse aspecto benéfico de uma estratificação social em formato de diamante e não piramidal.

Se a classe média é realmente uma classe tampão, então é esperado que essa classe tenha opiniões e preferências políticas mais moderadas do que as opiniões e preferências políticas das classes baixa e alta. 
Além disso, resta saber se de fato há maior heterogeneidade de interesses na classe média no Brasil. Por isso, há que se estudar a dispersão das opiniões em uma mesma classe. Mais especificamente, é importante atentar para as divergências intraclasse. A distribuição das opiniões entre seus membros é o indicador central da heterogeneidade valorativa de uma determinada classe. Assim, classes mais heterogêneas apresentam maior dispersão de suas preferências. No extremo, heterogeneidade deságua na indiferenciação entre as classes: algo que alerta parte da literatura internacional mais recente, descrente do poder explicativo da estratificação social sobre o comportamento político.

Indiretamente, os indicadores citados são referentes empíricos do potencial de tolerância de indivíduos. Mas há que se observar se esses atributos estão associados a posições substantivas sobre tolerância. $\mathrm{O}$ estudo da tolerância política é bem amplo e não existe claro consenso sobre a melhor definição e, ainda menos, sobre a mensuração mais adequada desse conceito (Kinder, 1998). Talvez a definição mais adotada na ciência política de hoje, mas não necessariamente consensual, seja aquela oferecida por Sullivan, Piereson e Marcus: “(...) tolerância implica na disposição para 'aceitar' aquelas coisas que um rejeita. Politicamente, isso implica na disposição para permitir a expressão dessas ideias ou interesses que um opõe (...)" (1979:784) ${ }^{6}$.

Essa definição de tolerância política implica, em parte, que um indivíduo tolerante é aquele que possui a boa vontade de conceder direitos civis para todos os membros da sociedade. Isso inclui liberdades políticas, como aquela de livre expressão, mesmo para os adversários políticos. Em suma, testaremos aqui as seguintes hipóteses, que pretendem suprir lacunas no estudo atual dos efeitos políticos da estratificação e mobilidade social no Brasil:

1) De acordo com a literatura sobre as bases econômicas e sociais da democracia e na teoria da modernização, argumentamos que a classe média é mais tolerante, dado indicado tanto por suas posições substantivas quanto pelos atributos de suas atitudes: mais moderadas, em contraposição à extremas, e mais indefinidas e abertas, operacionalizadas como não opiniões.

2) A heterogeneidade de preferências deve ser maior na classe média, indicando sua capacidade de compreensão e absorção de diferentes visões de mundo. Isso, por um lado, pode atenuar as diferenças entre classes e diminuir o potencial diferenciador da variável "estratificação". Devemos esperar níveis mais altos de heterogeneida- 
de, de dispersão das opiniões, entre membros da classe média. Caberá ver o grau dessa heterogeneidade para melhor definir se classe de fato importa ou se de tão heterogênea, já não discrimina.

3) Por último, a questão pode ser uma de mobilidade social, e não de estratificação. A mobilidade social tem sido vista como importante para alterar ordens políticas, inaugurando ou consolidando processos de inclusão seletiva de novos setores ao jogo político. Assim, é possível que mobilidade seja um determinante mais forte das atitudes políticas do que a estratificação social.

Por outro lado, em se confirmando as hipóteses nulas, levantamos suspeitas acerca do crescente consenso na literatura de que há algo de especial e particular na nova classe média brasileira. Conforme já apontamos, estudos anteriores no Brasil não utilizaram estratégias de mensuração e análise parecidas com a aqui adotada e foram precipitados em afirmar categoricamente as distinções existentes. Cabe indagar se as diferenças persistem em testes ligeiramente mais robustos e um desenho que realmente compara atitudes e seus atributos entre diferentes classes sociais e padrões de mobilidade social.

\section{DADOS E ANÁLISE: NÃO OPINIÃO, EXTREMISMO DAS OPINIÕES, TOLERÂNCIA}

Para avaliar as hipóteses apresentadas na seção anterior, usamos dados do Barômetro das Américas de 2012, que permite operacionalizar os conceitos de classe social, mobilidade social, não opiniões, extremismo de atitudes, heterogeneidade atitudinal e tolerância. O Barômetro das Américas é um estudo pan-americano conduzido bienalmente com amostras nacionais representativas de cada país das Américas (norte, central e sul) e alguns do Caribe. O questionário inclui diversos temas, como avaliação de governos e políticas públicas, apoio à democracia e às instituições democráticas, situação econômica pessoal e percepções sobre a economia nacional, dentre outros ${ }^{7}$. Dada a nossa ênfase no caso brasileiro, usaremos dados apenas do país que apresenta amostra de 1.500 pessoas entrevistadas no mês de abril de 2012 em 111 municípios distribuídos pelas cinco regiões, $12 \%$ em áreas rurais.

\section{Classes Sociais e Mobilidade Social no Brasil}

Adotamos aqui uma definição de classe social baseada no patrimônio (assets), como é feito por vários estudos para medir riqueza (wealth) 
(Córdova, 2009; Vyass e Kumaranayake, 2006; McKenzie, 2005; Minujin e Bang, 2002; Filmer e Pritchett, 2001) e seguimos a linha do Critério Brasil (ABEP) e do Critério de Classificação Econômica Brasil (CCEB). Infelizmente não é adequado usar dados de renda individual para mensurar classe usando os dados do Barômetro das Américas. Especificamente, a escala de respostas oferecidas no estudo apresenta categorias que não permitem uma boa discriminação entre os indivíduos de renda superior. Assim, segundo o Barômetro das Américas, $30 \%$ dos brasileiros teriam renda na categoria superior da escala ("mais de R $\$ 1.860 "$ "), sobre-estimando a classe alta e impossibilitando discriminá-la adequadamente. Outra alternativa é usar dados de classe social autodeclarada. Contudo, esse tipo de medida tende a sobrerrepresentar o pertencimento às classes média e média-baixa e reduzir enormemente o pertencimento à classe alta. Quando definida em quatro classes, combinando média-alta com alta, a correlação entre classe autodeclarada e aquela medida por bens e escolaridade é de 0,49. A correlação é positiva, como esperado, mas não é particularmente alta pelas razões elaboradas acima. Contudo, a percepção de posicionamento em classes sociais, apesar de medida válida também para classificar indivíduos, por ser subjetiva, sofre de maiores impressões que as medidas baseadas em bens e escolaridade. Por esses motivos, adotamos a já amplamente aceita mensuração de classe social com base em bens.

Concretamente, construímos uma variável que contabiliza os bens de consumo disponíveis no domicílio. Para cada item é atribuído valor 1. Para itens mais caros e raros atribuímos valor 2, para melhor discriminar as classes sociais ${ }^{8}$. Por último, acrescentamos a essa escala aditiva um valor indicando o nível de escolaridade do chefe da família. Precisamente, soma-se o número de anos de escolaridade do chefe de família dividido por 2. Assim, um chefe de família com 12 anos de escolaridade, ou seja, o equivalente ao ensino médio completo, recebe o valor de $6^{9}$.

A distribuição dessa escala é apresentada na Figura 1, onde é possível notar que a distribuição do patrimônio tende a uma distribuição normal. O valor mínimo observado dessa variável é igual a 2 e o valor máximo é 30,5. A média é de 16 e o desvio padrão de cerca de 6. Ou seja, os dados do Barômetro das Américas apontam para um país em 2012 com setores médios da sociedade em maior número do que valores extre- 
Figura 1

A Distribuição de Patrimônio no Brasil

(2012)

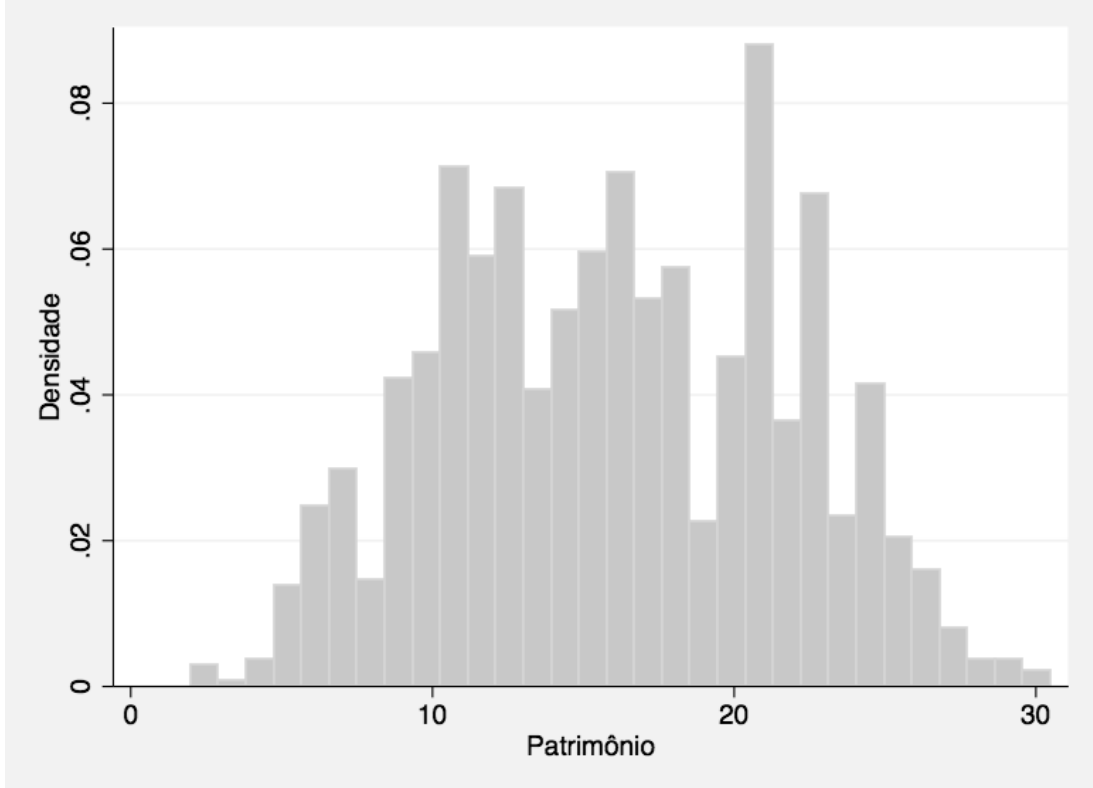

Fonte: Barômetro das Américas (2012).

mos. Logo, estamos próximos de uma distribuição em forma de diamante, com valores extremos sendo raros.

A partir dessa variável, classificamos os entrevistados em quatro grupos iguais de classe baseados na diferenciação da população em quartis. Em particular, a classe baixa é composta por indivíduos que obtiveram o valor de 11 pontos ou menos na escala de patrimônio, a classe média-baixa é constituída pelos que tiveram um valor entre 11 e 16, a classe média por aqueles entre 16 até 20,5 e, por último, a classe alta é definida pelos que obtiveram um valor de 21 pontos ou mais.

Para mensurar a mobilidade social ascendente de 2004 a 2012, usamos dados de variáveis que medem a classe social autodeclarada em dois períodos do tempo. Infelizmente não temos informações sobre o patrimônio dos entrevistados em 2004 para comparar com os valores de 2012, por isso a mobilidade social foi calculada de outra maneira, utilizando duas perguntas que aferiram a classe social à qual os entrevistados pertenciam em 2004 e aquela à qual pertencem hoje. A mobilidade social ascendente refere-se então a todos que indicaram pertencer a 
uma classe social superior em 2012 quando comparada à classe social de pertencimento em 2004. O resultado indica que pouco mais de 24,1\% dos brasileiros vivenciaram ascensão social entre 2004 e 2012. Em comparação, apenas 4,5\% experimentaram processos de retrocesso social. Os outros $71,6 \%$ mantiveram-se estáveis, segundo sua própria percepção.

\section{Não Opiniões}

A Tabela 1 apresenta estatísticas sobre a não opinião por classe baixa, média-baixa, média e alta. Assim, começamos a testar a hipótese 1 medindo se brasileiros de distintas classes sociais apresentam opiniões sobre diversos temas políticos e sociais.

Os resultados estão organizados segundo o tipo de opiniões apresentadas, com base em cinco categorias. A primeira trata das opiniões relativas ao apoio ao sistema democrático e aos valores democráticos de modo geral. Nessa categoria, por exemplo, encontram-se itens sobre apoio às "regras" do jogo democrático, como garantir os direitos dos partidos da oposição e limitar o papel dos militares. Na segunda categoria, agrupamos os itens relacionados às opiniões acerca da avaliação de governos (central, estadual e municipal) no combate à pobreza e à corrupção. Na terceira, acrescentamos as opiniões relativas às avaliações das instituições políticas. Essa categoria inclui, por exemplo, grau de confiança nos tribunais de justiça, Congresso Nacional etc. Na quarta categoria estão inclusas as opiniões sobre avaliação de políticas públicas, como a qualidade das escolas públicas e dos serviços de saúde pública. E, por último, a quinta categoria agrupa os itens que mensuram as preferências políticas dos entrevistados sobre o papel do Estado na economia. O Apêndice apresenta a lista das perguntas consideradas em cada categoria.

Os resultados da Tabela 1 apresentam claras evidências de que a não opinião diminui com base na situação socioeconômica dos indivíduos. Para as cinco categorias de opiniões consideradas, observamos que a porcentagem de indivíduos que não opinaram é sistematicamente menor a cada movimento entre classe social. Assim sendo, os membros da classe média-baixa sempre expressam menos não opiniões que os membros da classe baixa e os membros da classe média também menos que os membros da classe média-baixa. Os membros da classe alta, por sua parte, ora expressam ligeiramente menos não opiniões que os 
Lucio Rennó e Mathieu Turgeon

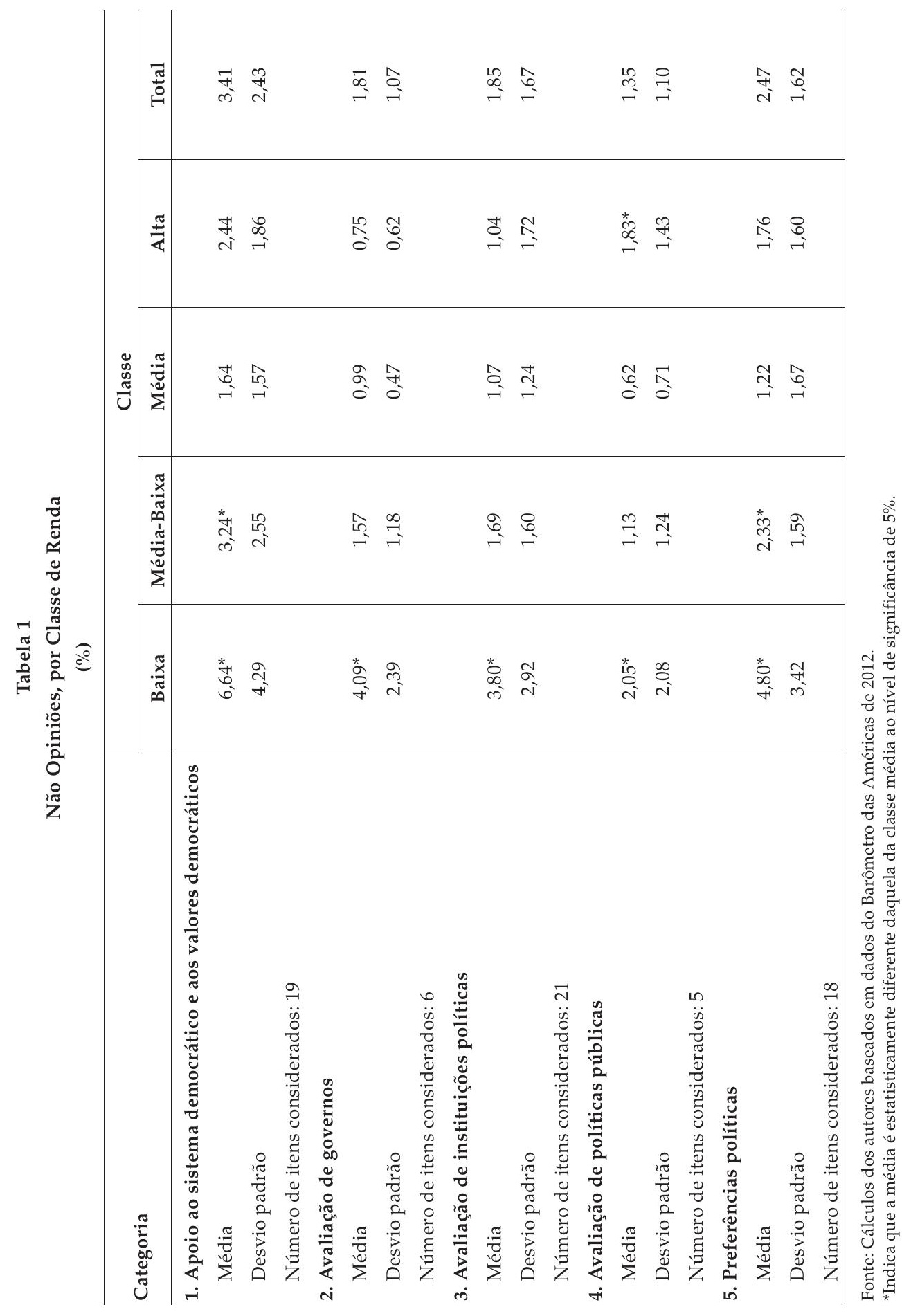


membros da classe média e ora expressam ligeiramente mais não opiniões. Porém, a não opinião entre esses dois grupos, quando comparados com os membros da classe baixa e média-baixa, é sempre inferior e raramente significativa em nossos testes estatísticos.

Mais importante, observamos que o grande salto na redução das não opiniões ocorre entre os membros da classe baixa para a classe média-baixa. No caso, as não opiniões são mais de duas vezes menos frequentes entre os membros da classe média-baixa $(2,24 \%)$ quando comparados com os membros da classe baixa $(4,74 \%)$. De qualquer forma, tende a prevalecer a ideia de que os ganhos de acesso à informação oriundos da melhora da condição social têm impacto na formação das opiniões de forma linear. Isso significa que a classe média não tem como traço marcante uma postura mais indefinida sobre temas sociais, que poderia indicar maior abertura atitudinal. Na verdade, a linear redução da não opinião por classe social - lembrando que a medida inclui o grau de instrução formal do chefe da família - indica que a capacidade de expressar opinião é um fator decorrente do acesso à informação que acompanha o aumento da capacidade de aquisição de bens no domicílio e do nível de escolaridade.

Por último, cabe comentar que há diferenças estatisticamente significativas entre a classe média e a classe baixa em todas as variáveis medidas, mas não em relação às outras classes sociais. Os testes de diferença de médias contrastaram a classe média a cada uma das outras classes sociais. Em geral, a lógica de diminuição linear da não opinião ocorre nas dimensões 2 e 3 abaixo. Nas demais, a classe média tem o menor índice de não opinião. De qualquer forma, a classe média se assemelha mais à classe alta do que às demais classes. A grande diferença, dado o conjunto da análise, é o alto índice de não opinião da classe baixa.

A hipótese 1 também desenvolve o argumento que a classe média, por ser mais heterogênea do que as classes baixa e alta, tem opiniões políticas mais moderadas do que as outras classes de renda. É concebível imaginar, por exemplo, que os membros da classe alta e baixa tenham atitudes mais intensas referentes a políticas redistributivas, em polos opostos da distribuição de opiniões sobre o tema. Membros da classe média, por sua vez, teriam atitude mais moderada e menos radical.

A Tabela 2, por sua vez, apresenta o extremismo das opiniões dos membros das quatro classes de renda com respeito a cinco itens. Nesses itens, os entrevistados foram solicitados a indicar o seu grau de concor- 
dância ou discordância com cada um dos enunciados numa escala de sete pontos variando entre "discordo muito" (1) e "concordo muito" (7). Para medir o grau de extremismo das opiniões e examinar se existe polarização das mesmas entre as classes de renda, subtraímos a opinião de cada respondente do valor do meio da escala (4). Assim, valores negativos indicam concordância com o enunciado da questão e valores positivos, discordância. Quanto mais afastado de 0 for o valor obtido, maior é o extremismo (intensidade) da opinião do entrevistado, ou em direção à concordância (até -3) ou da discordância (até +3). A Tabela 2 apresenta a média desses valores para os membros de cada classe de renda.

O primeiro item enfoca as atribuições do Estado em garantir o bem-estar das pessoas. Esse item não apresenta diferença notável entre as classes de renda. As quatro classes consideradas (baixa, média-baixa, média e alta) mostram opiniões similares: os membros de todas geralmente concordam com a ideia de que "o Estado, mais que os indivíduos, deve ser o responsável principal pela garantia do bem-estar das pessoas". Na verdade, a classe que mais concorda com esse enunciado (embora a diferença seja pequena) é a classe baixa, e aquela que menos concorda é a classe alta. Sobre esse item, então, não observamos opiniões muito extremas e nada de polarização das opiniões entre as classes.

O segundo item da tabela contrasta a responsabilidade do Estado e da iniciativa privada em criar empregos. Novamente, observamos mais semelhanças do que diferenças entre classes. Não há polarização marcantes das opiniões entre as classes. Se há alguma diferença causada por classe, ela se limita às visões da classe baixa, sempre mais extremadas acerca do papel redistributivo do Estado.

O terceiro pergunta sobre o papel do Estado em implementar políticas públicas para reduzir a desigualdade de renda entre ricos e pobres. Mais uma vez todas as classes sociais concordam que o Estado deve implementar políticas firmes para reduzir a desigualdade de renda entre ricos e pobres. As diferenças de opinião entre as quatro classes de renda são pequenas, e observamos um certo extremismo, com um grau de concordância relativamente alto. Há um consenso predominante na sociedade brasileira sobre a necessidade de inclusão social.

Já o quarto item indaga sobre o papel do Estado, quando comparado como o setor privado, no provimento de serviços de saúde. Os membros de todas as classes de renda possuem opiniões parecidas e acredi- 
A Psicologia Política das Classes Sociais no Brasil

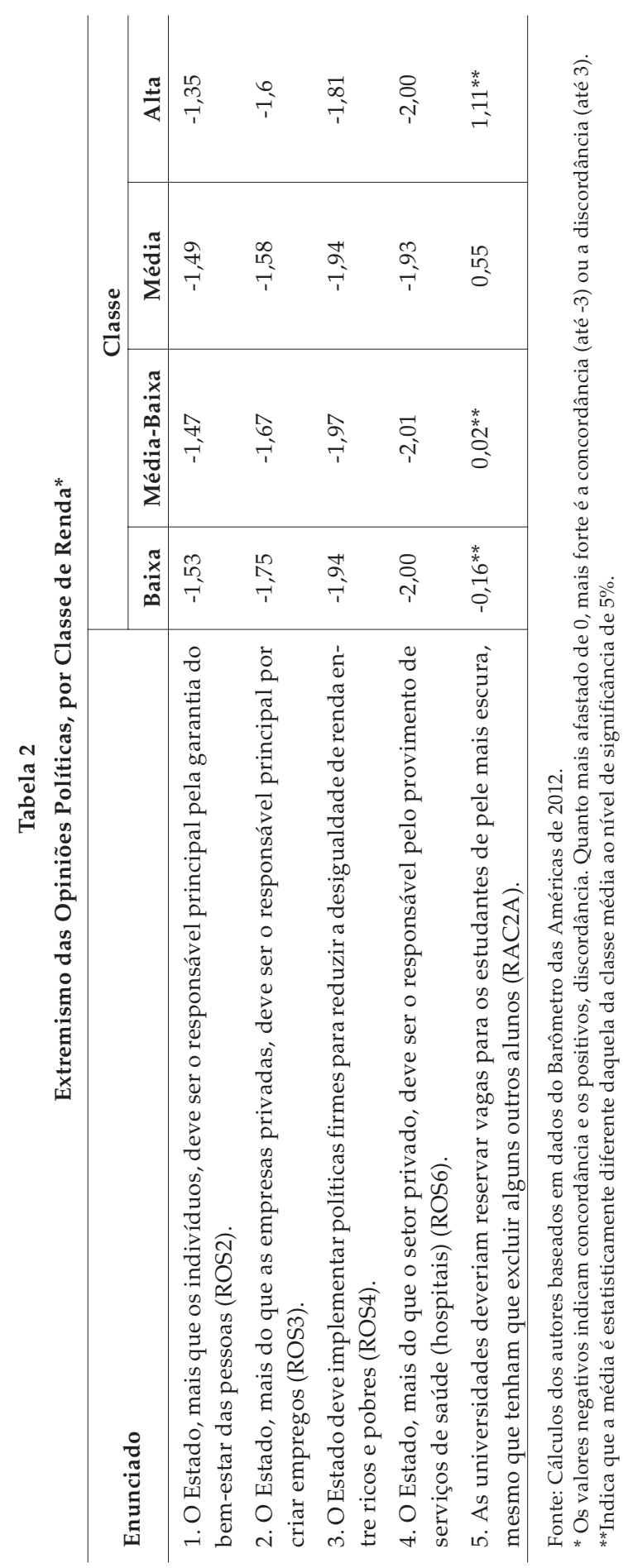

DADOS - Revista de Ciências Sociais, Rio de Janeiro, vol. 59, nํㅡ, 2016 
tam que o Estado deve ser responsável pelo provimento de serviços de saúde. Não observamos polarização das opiniões entre as classes de renda.

Finalmente, o quinto e último item é mais específico do que os outros apresentados até agora, e pergunta sobre a adoção de uma política de cotas para estudantes afrodescendentes no ingresso às universidades públicas. Esse item apresenta uma polarização ligeiramente mais alta entre os membros das classes baixa e alta. Mais especificamente, os membros da classe baixa não possuem opinião bem definida, concordando muito pouco com a adoção de uma política de cotas. O mesmo se observa entre os membros da classe média-baixa. São os membros da classe alta os menos favoráveis à política de cotas raciais. Os membros da classe média também tendem a discordar ligeiramente dessa política. Seguramente, nenhum dos grupos demonstra extremismo de opinião. A classe média, novamente, não é diferente dos demais grupos: não é mais moderada. Há um grupo mais claramente contrário os mais ricos - mas nenhuma outra diferença perceptível.

Nossos testes de diferença de médias mostram classes muito parecidas entre si. Apenas o item sobre cotas raciais contrasta a classe média das demais. As posições mais extremas e contrárias a essa política são da classe alta. Já a classe baixa é mais claramente favorável. Esse é o único tema que apresenta diferenciação entre classes sociais.

As análises apresentadas anteriormente sobre o extremismo das opiniões dos membros das diferentes classes de renda e sobre a possível polarização dessas opiniões entre as classes rejeitam a primeira hipótese derivada da literatura. Não há polarização das opiniões entre os membros das classes baixa e alta e os membros da classe média não possuem opiniões mais moderadas.

A hipótese 1, por último, também ressalta que o conteúdo substantivo das preferências dos membros das diferentes classes sociais pode ser distinto. Já indicamos acima que esse conteúdo, no que tange ao papel redistributivo do Estado, não diferencia profundamente as classes sociais. Todos, no Brasil, defendem um Estado interventor: dos mais abastados aos mais pobres. A Tabela 3 a seguir apresenta cinco itens que buscam mensurar o grau de tolerância dos membros das quatro classes sociais baseados no conteúdo de suas opiniões. Ou seja, voltamos nosso olhar agora para aspectos substantivos das opiniões das distintas classes. Os quatro primeiros itens mensuram o grau de 
A Psicologia Política das Classes Sociais no Brasil

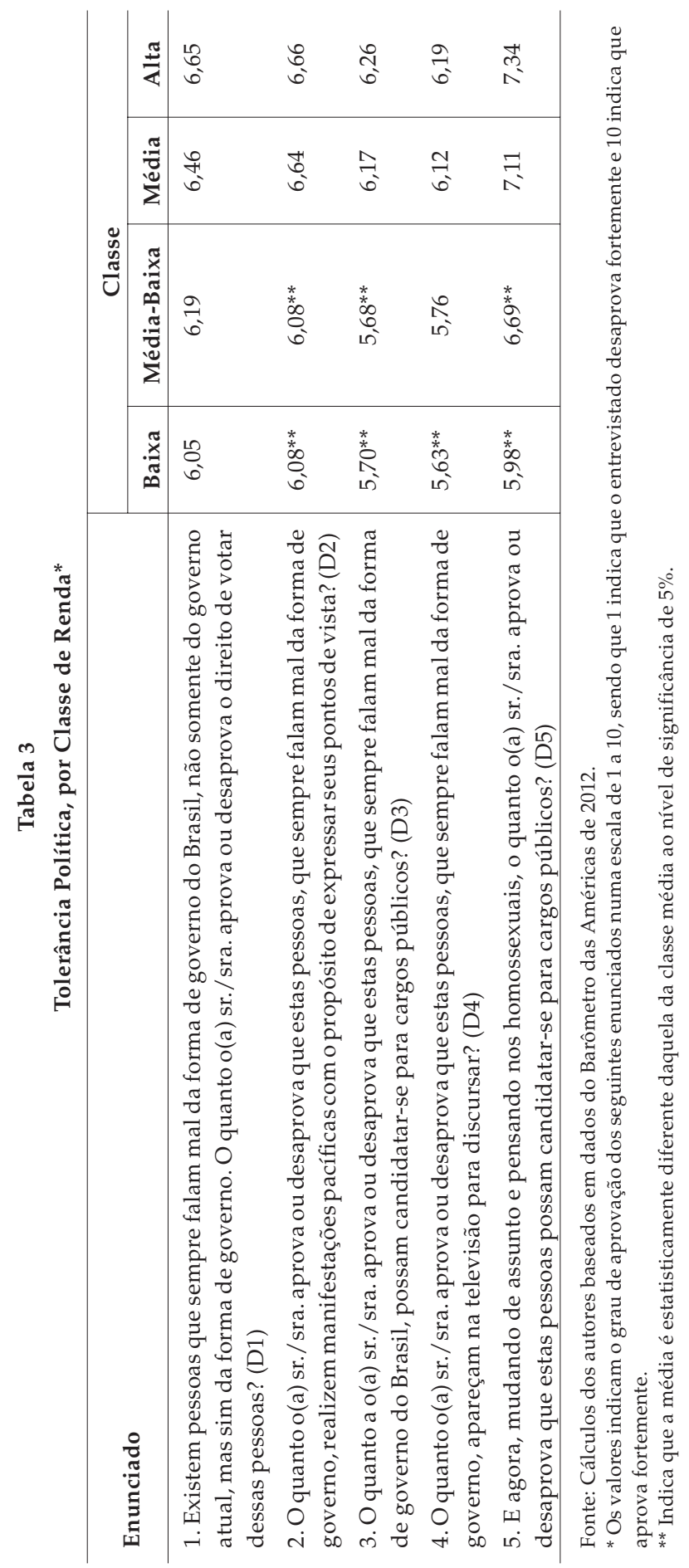

DADOS - Revista de Ciências Sociais, Rio de Janeiro, vol. 59, nํㅡ, 2016 
concordância com a concessão de direitos a "pessoas que sempre falam mal da forma de governo do Brasil". O primeiro item evoca o direito de votar dessas pessoas; o segundo problematiza o direito de realizar manifestações pacíficas com o propósito de expressar seus pontos de vista; o terceiro toca no direito de candidatar-se a cargos públicos; o quarto volta-se para o direito de aparecer na televisão para discursar. $\mathrm{O}$ último item pergunta ao entrevistado se ele aprova ou desaprova o direito de os homossexuais poderem se candidatar a cargos públicos. Esses itens medem o grau de tolerância política da cidadania brasileira.

Os resultados da Tabela 3 são claros e indicam de maneira sistemática que a tolerância aumenta com a classe social das pessoas. De forma linear, os membros da classe média-baixa são mais tolerantes que os membros da classe baixa, os membros da classe média mais tolerantes que os membros da classe média-baixa, e os membros da classe alta mais tolerantes que os membros da classe média. Ou seja, repete-se o padrão encontrado na discussão sobre não opinião. Como o anterior, o resultado é mais consoante com achados de autores que mostraram empiricamente que a tolerância é uma função positiva do grau de escolaridade formal de uma pessoa (Bobo e Licari, 1989), o qual é altamente relacionado com a classe social. Portanto, não se trata de atributo específico de classe, mas sim de outras variáveis. As classes média e média-baixa não têm nada em particular que as diferencie das demais classes sociais.

Os testes estatísticos, por sua vez, mostram que a classe média, no que tange à tolerância política, se parece bem mais com a classe alta do que com a média e média-baixa. Ou seja, não há uma particularidade da classe média. Ela se assemelha à classe alta e se diferencia das classes mais baixas. A divisão parece ser bem mais clara entre dois grupos - ricos e pobres - e não entre três ou quatro.

A segunda hipótese norteadora, provinda da literatura, aponta para uma maior heterogeneidade de preferências nos setores intermediários da estratificação social. Na verdade, as visões sobre tolerância, operacionalizadas acima tanto pelo conteúdo substantivo das opiniões quanto pelos atributos das mesmas, se não cristalizadas e abertas (indicadas pela não opinião) e moderadas, em oposição às extremas, estão relacionadas à ideia de que a classe média incorpora pessoas com visões e trajetórias de vida diversas. Estatisticamente podemos captar 
essa diversidade através de medidas de dispersão das opiniões dentro de cada classe social. Assim, voltamos nosso olhar para como as opiniões se estruturam dentro de classes e não entre classes. $O$ desvio padrão nos indica o grau de heterogeneidade intraclasse, que é importante para desvendarmos o compartilhamento das visões de mundo em uma mesma classe.

Em seguida, a Tabela 4 apresenta o desvio padrão das opiniões em cada classe social de inúmeros itens do questionário do Barômetro das Américas sobre as diversas temáticas que tratamos acima ${ }^{10}$. A primeira parte da tabela indica as diferenças entre classes sociais, e a segunda metade, aquelas entre diferentes padrões de mobilidade social, operacionalizando assim também a hipótese 3 .

Comentaremos, primeiramente, aspectos relacionados com a hipótese 2, de que há maior heterogeneidade e, portanto, desvio padrão mais acentuado, na classe média. Essa hipótese tampouco é confirmada pelos achados. As diferenças entre classes do grau de heterogeneidade intraclasse são sempre pequenas. Se há um grupo mais heterogêneo, este é a classe baixa, que sempre se diferencia mais acentuadamente dos demais. Ou seja, em mais este atributo das opiniões, a classe média e média-baixa não se destacam como diferentes. Há, na verdade, uma relação linear sutil que leva a menos heterogeneidade nas classes mais altas e mais heterogeneidade nas mais baixas. Apenas nos itens que medem tolerância há uma inversão na direção dessa relação, com as classes mais altas sendo mais heterogêneas. De toda sorte, mais uma vez rejeitamos a hipótese de que há algo especial nos setores intermediários das classes sociais brasileiras.

Começamos, finalmente, a testar a hipótese 3 , de que a mobilidade social seria mais relevante do que a estratificação social para explicar diferenças de opiniões. Em estudo pioneiro sobre isso, Peixoto e Rennó (2011) indicaram que os cidadãos que experimentaram processos de ascensão social nos governos petistas eram bem mais inclinados a votarem em Dilma Rousseff nas eleições de 2010. Cabe ver se esse padrão também afeta outras opiniões. A segunda parte da Tabela 4 diferencia aqueles que sentiram processos de mobilidade social ascendente e os demais. Não há nenhum indício sistemático de que a heterogeneidade desse grupo é maior do que a dos demais.

Por fim, as Tabelas 5, 6 e 7 apresentam nosso último teste da hipótese 3. Repetimos as análises que fizemos anteriormente para as variáveis de 


\section{Lucio Rennó e Mathieu Turgeon}

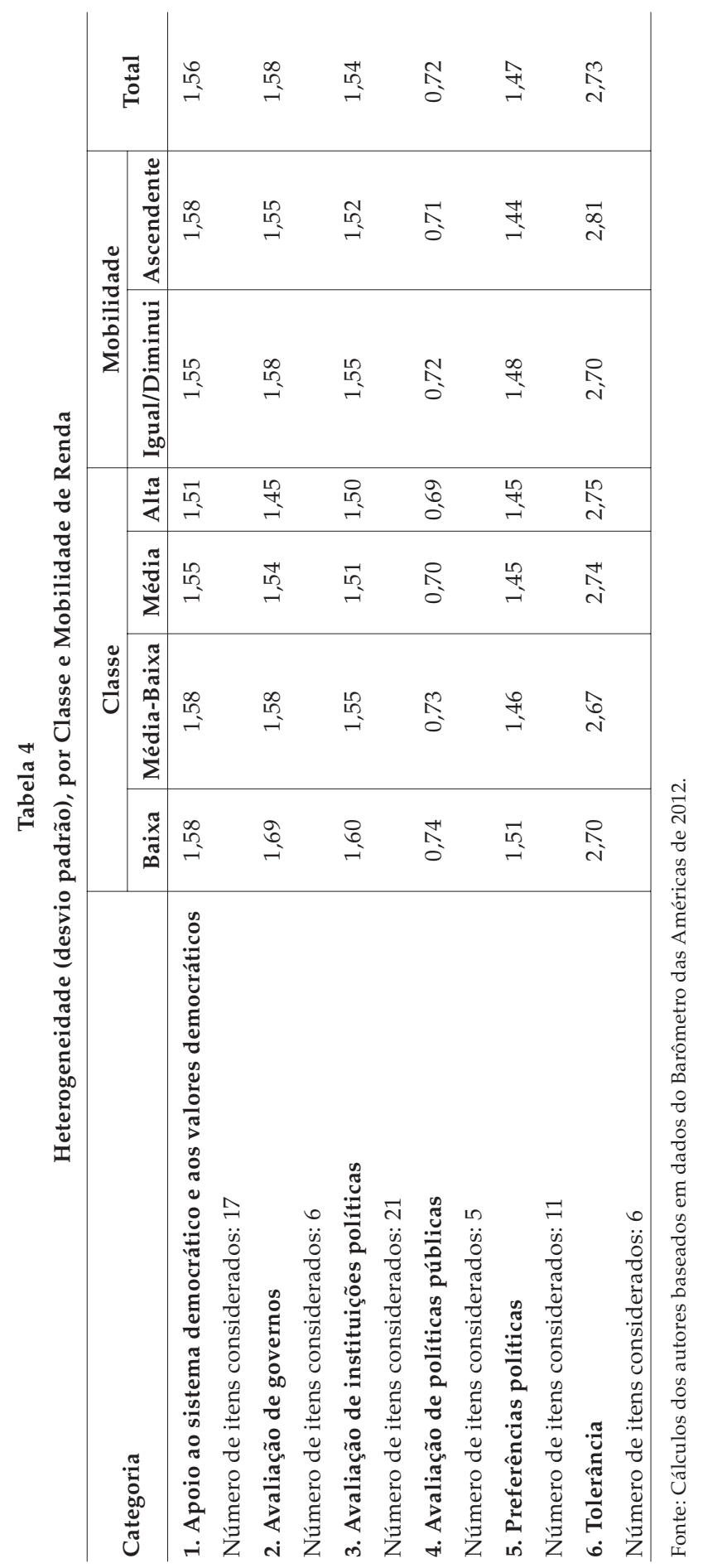


A Psicologia Política das Classes Sociais no Brasil

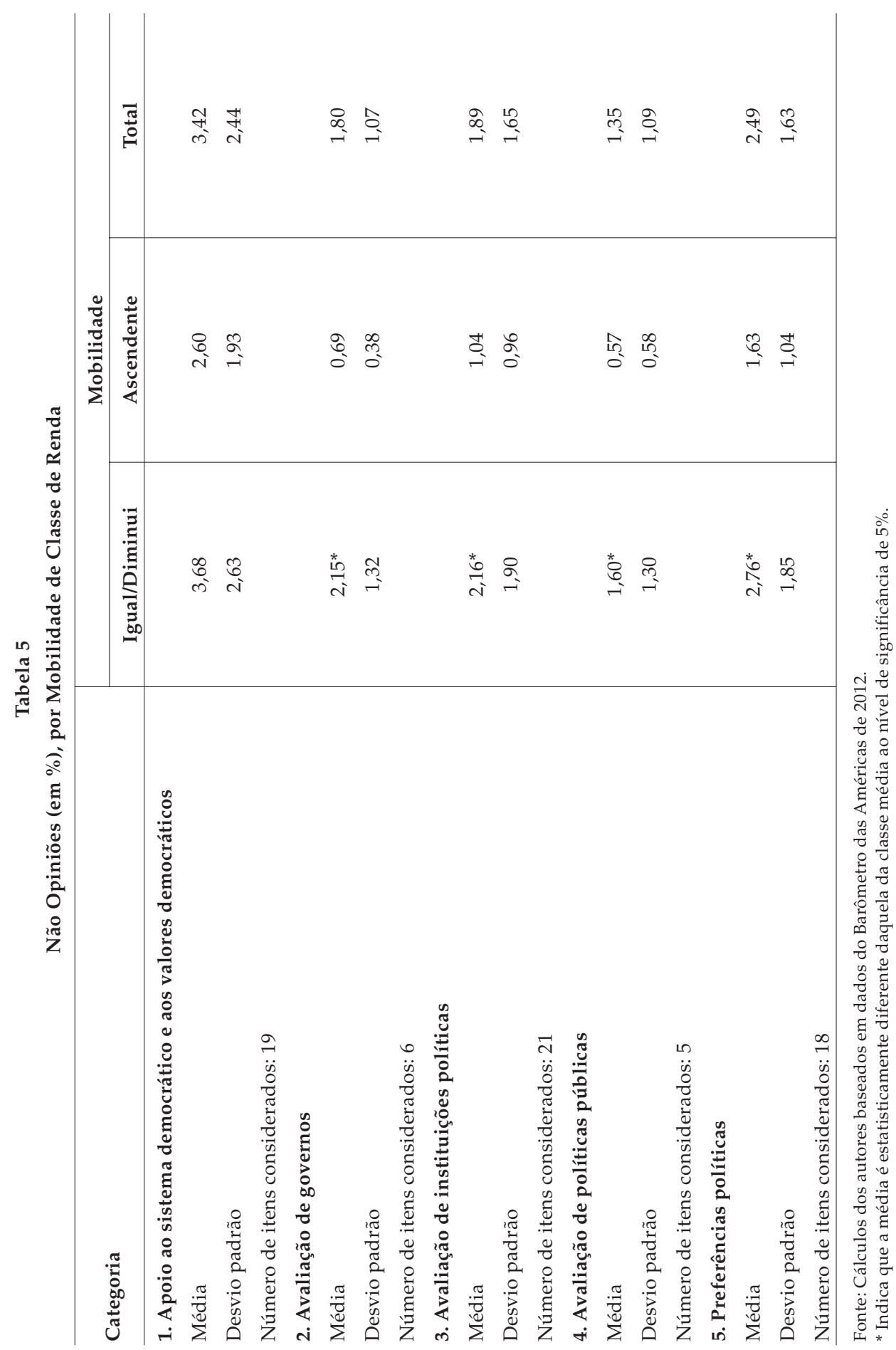

DADOS - Revista de Ciências Sociais, Rio de Janeiro, vol. 59, nํㅡ, 2016 


\section{Lucio Rennó e Mathieu Turgeon}

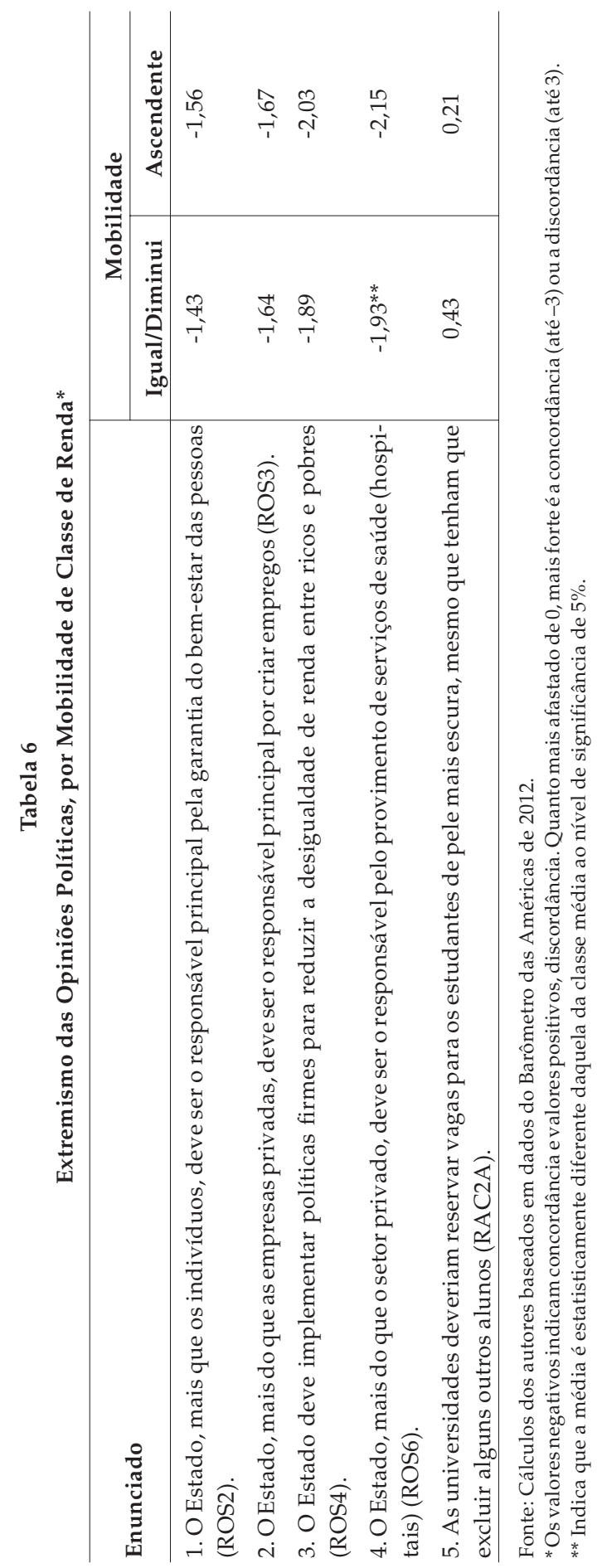


A Psicologia Política das Classes Sociais no Brasil

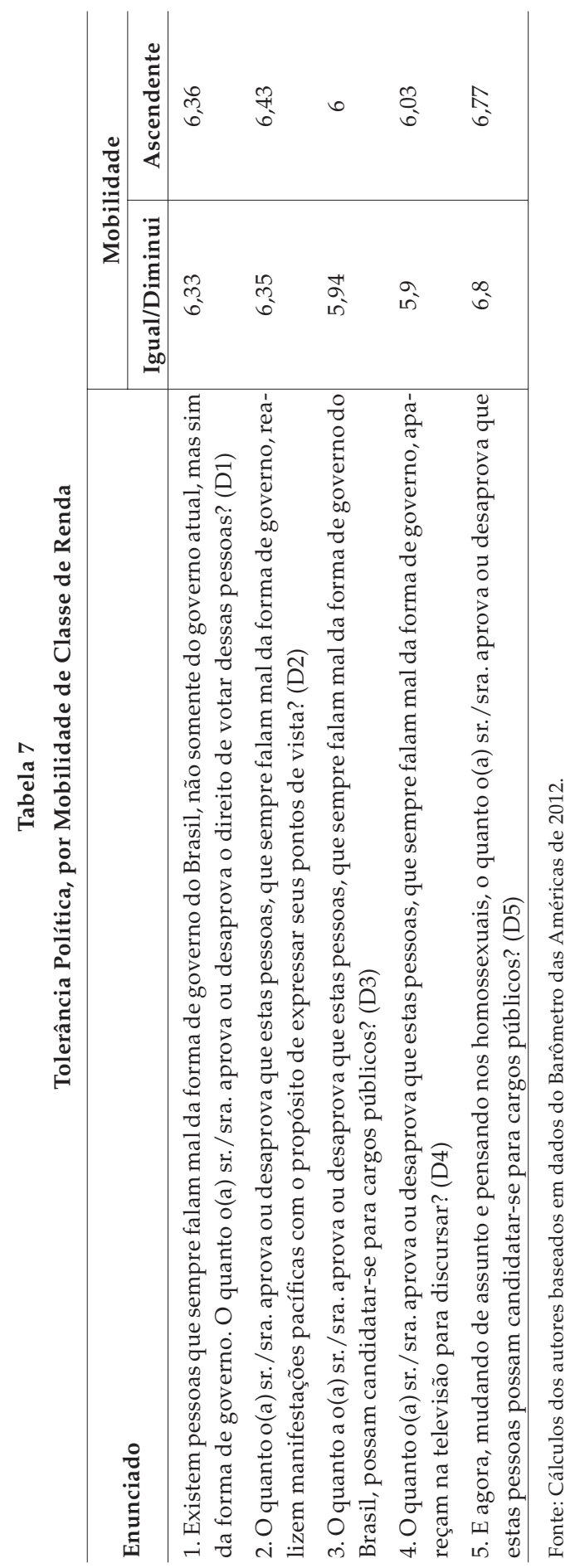

DADOS - Revista de Ciências Sociais, Rio de Janeiro, vol. 59, nํㅡ, 2016 
estratificação social para nosso indicador de mobilidade. Ou seja, pretendemos ver se aqueles que vivenciaram processos de mobilidade social ascendente são mais abertos (não opinião), mais moderados e têm opiniões mais tolerantes do que os que se sentiram estagnados ou com mobilidade decrescente.

A Tabela 5 aponta que há diferenças por mobilidade mais acentuadas do que por classe. Primeiro, as médias de não opinião por classe são sempre menores para os setores ascendentes e, segundo, a heterogeneidade dessa não opinião é sempre menor. Assim, setores ascendentes têm opiniões mais cristalizadas do que os demais e são mais coesos nessa postura. Isso é sinal de menor abertura dos setores ascendentes, ao contrário do que se esperaria com base em nossa interpretação da literatura, mas quanto ao conteúdo, mostram-se menos ambíguos em relação às instituições democráticas. As diferenças são estatisticamente significativas.

Na Tabela 6 exploramos o extremismo das opiniões por mobilidade social. As diferenças agora são bem mais sutis. A direção do extremismo de opiniões é semelhante para todos os grupos, algo que já havíamos constatado para as diferentes classes sociais. O grupo ascendente tende a ser mais extremo em suas opiniões favoráveis à intervenção do Estado, mas essas diferenças são sutis para a maioria dos itens, exceto quando perguntados sobre o provimento de serviços de saúde e a reserva de vagas, que por sinal indica postura contrária de ambos os grupos. No que tange à prestação de serviços de saúde, essa parece ser uma demanda bem mais clara dos setores ascendentes da sociedade brasileira. Já sobre as cotas, apesar de serem contrários, aqueles que viveram processos mobilidade social ascendente são menos extremos nessa visão. Na verdade, ambos os grupos parecem mais moderados nesse item do que nos outros, ou seja: novamente não vemos muita diferença entre setores com mobilidade ascendente e os demais.

Por último, avaliamos o conteúdo substantivo das opiniões dos dois grupos. Novamente constatamos que não há diferenças marcantes por grupos de mobilidade social. Ou seja, os processos recentes de melhoria da vida de setores da população brasileira ainda não surtiram efeito em suas visões de mundo, tornando-os mais tolerantes, mais abertos, moderados ou heterogêneos que outros setores da sociedade. Nossos testes de significância estatística não demonstram qualquer diferença entre as médias. Refutamos, assim, a hipótese 3. 


\section{CONSIDERAÇÕES FINAIS}

Neste artigo articulamos duas temáticas do estudo de comportamento político que não haviam dialogado antes visando substanciar hipóteses acerca da influência da estratificação social e mobilidade social em atitudes políticas da cidadania brasileira. Bebemos na fonte dos estudos clássicos e contemporâneos sobre classes sociais e política, com destaque para a recente literatura sobre "nova classe média" no Brasil e desenvolvemos hipóteses derivadas da incorporação de conceitos da psicologia política. Assim, testamos como o posicionamento em classes sociais e grupos que vivenciaram mobilidade social afetou atributos das atitudes políticas, como não opinião, extremismo atitudinal e heterogeneidade intraclasse de opiniões.

Nossos resultados não indicam fortes diferenças entre classes sociais e grupos de mobilidade social nem apontam nada de particular nos setores intermediários dos estratos sociais brasileiros. Isso contradiz frontalmente ampla literatura brasileira que tem argumentado haver algo de específico e especial na nova classe média, setores da população com mobilidade social ascendente e em camadas intermediárias da estratificação social. Não encontramos tais efeitos. Se há algum impacto da classe social, este é linear e gradual, movendo-se de comportamentos mais diferentes entre classes baixa e alta, com uma posição intermediária das classes média-baixa e média. Ou seja, parece ser mais razoável falar de uma classe baixa da população brasileira que não tem melhorado de vida nos últimos anos como distinta das demais. Classes médias compartilham visões de mundo com classes altas e os mais pobres se diferenciam dos demais. Parece haver uma divisão entre ricos e pobres em suas visões sobre política e sociedade no Brasil, mas a dita "nova classe média" não apresenta nada de novo ou particular.

(Recebido em junho de 2014)

(Reapresentado em outubro de 2015)

(Aprovado em dezembro de 2015)

DADOS - Revista de Ciências Sociais, Rio de Janeiro, vol. 59, nº 1, 2016 


\section{Lucio Rennó e Mathieu Turgeon}

\section{NOTAS}

1. Para exceções, veja Rennó (2007) e Batista (2013).

2. Cabe revisitar esse debate para entender a constituição dos valores sociais das distintas classes. Os yeoman eram produtores de bens agrícolas voltados para o comércio. Assim, o papel do comerciante passa a ser central, tanto nas cidades quanto nos campos, para a dinamização e mudança da estrutura econômica. Essa mudança de lógica está diretamente associada à construção da propriedade privada, os enclosures (ocupação de terras abandonadas ou coletivas), visando o lucro através da venda (comércio) de produtos. A terra deixa de ser usada para o autossustento e passa a ser vista como mercadoria que produz mercadorias. Por outro lado, a coroa tenta combater os enclosures, protegendo os camponeses e impondo pesadas multas aos yeoman. Isso, contudo, com baixa capacidade de implementação, devido à fragilidade organizacional do Estado na Inglaterra daquele período. O que a coroa conseguiu com sua política de perseguição aos yeoman foi uni-los em um discurso político voltado para a defesa da propriedade privada e de seus direitos de comércio de bens. Formaram uma oposição coerente e liberal à coroa.

3. No original: "a large middle class plays a mitigating role in moderating conflict since it is able to reward moderate and democratic parties and penalize extremist groups" (Lipset, 1959:83).

4. Responder a perguntas de surveys é algo cansativo e trabalhoso. Muitos entrevistados podem adotar uma estratégia de minimizar os esforços cognitivos exigidos para apresentar respostas "pensadas" sobre os itens. É o que o John Krosnick (1991) identifica como o survey satisficing. Essa tendência se manifesta de várias maneiras numa pesquisa de opinião pública, incluindo a maior probabilidade dos entrevistados de escolher a opção "Não sei" quando tal opção está ofertada na pergunta. Nesse sentido, é possível que alguns entrevistados indiquem não possuir opiniões sobre itens perguntados quando de fato eles possuem opiniões verdadeiras. O que sabemos, porém, é que essa tendência é maior quando a opção "Não sei" é ofertada no enunciado do item no questionário. Felizmente, isso não ocorre nos itens aqui analisados.

5. Atitudes mais moderadas, por outro lado, facilitam o diálogo, qualidade desejável em qualquer regime democrático (Dahl, 1956). O extremismo das opiniões políticas refere-se à situação onde as opiniões políticas se encontram longe de uma posição moderada. Por exemplo, uma pessoa que acredita que o Estado brasileiro deve reduzir em muito os gastos na saúde tem uma opinião mais extrema de que um indivíduo que acredita que o Estado deveria manter os gastos em saúde como estão. Similarmente, um indivíduo que acredita que toda atividade econômica precisa ser regulada pelo Estado tem uma opinião mais extrema que outro que acredita que algumas atividades econômicas, mas nem todas, precisam de regulamentação estatal.

6. No original: "[...] tolerance implies a willingness to 'put up with' those things that one rejects. Politically, it implies a willingness to permit the expression of those ideas or interests that one opposes" (Sullivan, Piereson e Marcus, 1979:784).

7. Maiores informações sobre o Barômetro das Américas estão disponíveis em www.americasbarometer.org

8. Os itens que receberam pontuação dobrada são: telefone em casa, carro, microondas, motocicleta, computador e internet em casa. 
9. Escolaridade é medida como o número de anos de atendimento à escola, e varia entre 0 e 18 anos. Como sua distribuição pode atingir valores muito altos, isso poderia ocasionar uma sobrerrepresentação do impacto dessa variável na medida de classe social. Por isso, dividimos seu valor absoluto por 2 .

10. Novamente, o Apêndice apresenta a lista completa das perguntas consideradas na Tabela 4. 


\section{Lucio Rennó e Mathieu Turgeon}

\section{REFERÊNCIAS BIBLIOGRÁFICAS}

ACEMOGLU, Daron; ROBINSON, James (2006), Economic Origins of Dictatorship and Democracy. Cambridge, Cambridge University Press.

ALMEIDA, Alberto. (2007), A Cabeça do Brasileiro. Rio de Janeiro, Record.

ALTHAUS, Scott L. (1996), “Opinion Polls, Information Effects and Political Equality: Exploring Ideological Biases in Collective Opinion". Political Communication, vol.13, pp. 3-21.

BATISTA, Frederico. (2013), "Sofisticação Política e Opinião Pública no Brasil: Revisitando Hipóteses Clássicas". Opinião Pública, vol. 19, no 2, pp. 291-319.

BISHOP, George; TUCHFARBER, Alfred; OLDENDICK, Robert. (1986), “Opinions on Fictitious Issues: The Pressure to Answer Survey Questions". Public Opinion Quarterly, vol. 50, pp. 240-250.

BOBO, Lawrence; LICARI, Frederick C. (1989), “Education and Political Tolerance: Testing the Effects of Cognitive Sophistication and Target Group Affect". Public Opinion Quarterly, vol. 53, pp. 287-308.

BOIX, Carles. (2003), Democracy and Redistribution. Cambridge, Cambridge University Press.

BRAGA, Ruy. (2012), A Política do Precariado: Do Populismo à Hegemonia Lulista. São Paulo, Boitempo.

BUTLER, David; STOKES, Donald. (1974), Political Change in Britain: The Evolution of Electoral Choice. London, Macmillan.

CONNER, Mark; ARMITAGE, Christopher J. (2008), "Attitudinal Ambivalence", in W. D. Crasno; R. Prislin (eds.), Attitudes and Attitude Change. New York, Psychology Press, pp. 261-288.

CÓRDOVA, Abby. (2009), "Methodological Note: Measuring Relative Wealth using Household Asset Indicators". AmericasBarometer Insights: 2008 (No.6).

DAHL, Robert A. (1956), A Preface to Democracy. Chicago, Chicago University Press.

DELLI CARPINI, Michael X.; KEETER, Scott. (1996), What Americans Know About Politics and Why It Matters. New Haven, Yale University Press.

FERREIRA, Francisco H. G. et al. (2013), Mobilidade Econômica e a Ascenção da Classe Média Latino-Americana. Washington, International Bank for Reconstruction and Development / The World Bank.

FILMER, Deon; PRITCHETT, Lant. (2001), “Estimating Wealth Effect without Expenditure Data or Tears: An Application to Educational Enrollments in States of India". Demography, vol. 38, no 1, pp. 115-132.

FOWLER, Floyd J. (1995), Improving Survey Questions: Design and Evaluation. Thousand Oaks, Sage Publications.

HANDLIN, Samuel. (2013), "Social Protection and the Politicization of Class Cleavages during Latin America's Left Turn". Comparative Political Studies, vol. 46, no 12, pp. 1582-1609. 
HUCKFELDT, Robert; SPRAGUE, John. (1995), Citizens, Politics, and Social Communication. Cambridge, Cambridge University Press.

KELLEY, Jonathan; McALLISTER, Ian. (1985), "Social Context and Electoral Behavior in Britain". American Journal of Political Science, vol. 29, no 3, pp. 564-586.

KINDER, Donald R. (1998), “Opinion and Action in the Realm of Politics”, in D. T. Gilbert et al. (eds.), Handbook of Social Psychology (4a ed.). Oxford, Oxford University Press.

KRIECKHAUS, Jonathan et al. (2014), "Economic Inequality and Democratic Support". The Journal of Politics, vol. 76, no 1, pp. 139-151.

KROSNICK, Jon A. (1991), "Response Strategies for Coping with the Cognitive Demands of Attitude Measures in Survey". Applied Cognitive Psychology, vol. 5, no 3, pp. 213-236.

;MILBURN, Michael. (1990), “Psychological Determinants of Political Opinionation". Social Cognition, vol. 8, pp. 49-72.

KUKLINSKI, James H. (2002), Thinking about Political Psychology. Cambridge, Cambridge University Press.

KUNDA, Ziva. (1990), “The Case for Motivated Reasoning". Psychological Bulletin, vol. 108, no 3, pp. 480-498.

LANGTON, Kenneth P.; RAPOPORT, Ronald. (1975), "Social Structure, Social Context, and Partisan Mobilization: Urban Workers in Chile". Comparative Political Studies, vol. 8, pp. 318-344.

LIPSET, Seymour M. (1959), "Some Social Requisites of Democracy: Economic Development and Political". The American Political Science Review, vol. 53, no 1, pp. 69-105.

LUSKIN, Robert C. (1990), "Explaining Political Sophistication”. Political Behavior, vol. 12, no 4, pp. 331-361.

MCKENZIE, David J. (2005), "Measuring Inequality with Asset Indicators". Journal of Population Economics, vol. 18, no 2, pp. 229-260.

MINUJIN, Alberto; BANG, Joon Hee. (2002), “Indicadores de Inequidad Social. Acerca del uso del Índice de Bienes para la Distribución de los Hogare". Desarrollo Económico, vol. 42, no 165, pp. 129-146.

MOORE, Barrington. (1983), As Origens Sociais da Ditadura e da Democracia: Senhores e Camponeses na Construção do Mundo Moderno. São Paulo, Martins Fontes.

NERI, Marcelo C. (coord.). (2010), A Nova Classe Média. O Lado Brilhante dos Pobres. Rio de Janeiro, FGV/CPS, 2010.

PEIXOTO, Vitor; RENNÓ, Lucio. (2011), “Mobilidade Social Ascendente e Voto: As Eleições Presidenciais de 2010 no Brasil”. Opinião Pública, vol.17, pp. 304-332.

REDLAWSK, David P. (2002), “Hot Cognition or Cool Consideration? Testing the Effects of Motivated Reasoning on Political Decision Making". The Journal of Politics, vol. 64, no 4, pp. 1021-1044.

RENNÓ, Lucio. (2007), “Desigualdade e Informação Política: As Eleições Brasileiras de 2002". DADOS - Revista de Ciências Sociais, vol. 50, no 4, pp.721-755.

DADOS - Revista de Ciências Sociais, Rio de Janeiro, vol. 59, nº 1, 2016 


\section{Lucio Rennó e Mathieu Turgeon}

; AMES, Barry. (2014), “PT no Purgatório: Ambivalência Eleitoral no Primeiro Turno das Eleições Presidenciais de 2010". Opinião Pública, vol. 20, pp. 1-25.

SCHUMAN, Howard; PRESSER, Stanley. (1981), Questions and Answers in Attitude Surveys: Experiments on Question Form, Wording and Content. New York, Academic Press.

SINGER, André. (2009), “Raízes Sociais e Ideológicas do Lulismo”. Novos Estudos Cebrap, vol. 95, pp. 83-103.

(2012), Os Sentidos do Lulismo: Reforma Gradual e Pacto Conservador. São Paulo, Companhia das Letras.

SOUZA, Amaury de; LAMOUNIER, Bolívar. (2010), A Classe Média Brasileira: Ambições, Valores e Projetos de Sociedade. Rio de Janeiro, Elsevier.

SOUZA, Jessé. (2012), Os Batalhadores Brasileiros: Nova Classe Média ou Nova Classe Trabalhadora? Belo Horizonte, Editora UFMG.

SULLIVAN, John L.; PIERESON, James; MARCUS, George E. (1979), “An Alternative Conceptualization of Political Tolerance: Illusory Increases 1950s-1970s". The American Political Science Review, vol. 73, no 3, pp. 781-794.

THORNTON, Judd R. (2011), “Ambivalent or Indifferent? Examining the Validity of an Objective Measure of Partisan Ambivalence". Political Psychology, vol. 32, no 5, pp. 863-884.

VYASS, Seema; KUMARANAYAKE, Lilani. (2006), “Constructing Socioeconomic Status Indexes: How to Use Principal Component Analysis". Health Policy and Planning, vol. 21, no 6, pp. 459-468. 


\section{APÊNDICE}

Segue a descrição detalhada sobre as perguntas do questionário do Barômetro das Américas (BA) consideradas em cada uma das categorias das Tabelas 1 e 2 . O questionário completo encontra-se no seguinte site: http://www. vanderbilt.edu/lapop/core-surveys.php

1. Apoio ao sistema democrático e aos valores democráticos: POP101, ING4, DEM23, JC1, JC10, JC13, JC15A, JC16A, VOL205, AOJ8, E3, E5, E8, E11, E14, E15, E16, DEM2 e AUT1.

2. Avaliação de governos: N1, N3, N9, N11, N15 e M1.

3. Avaliação de instituições políticas: B1, B2, B3, B6, B10A, B11, B12, B13, B18, B21, B21A, B31, B32, B37, B47A, B3MILX, AOJ12, AOJ18, M2, PN4 e PN5.

4. Avaliação de políticas públicas: SC2NEW2, SD3NEW2, SD6NEW2, SOC3 e SOC7.

5. Preferências políticas: ROS1, ROS2, ROS3, ROS4, ROS6, RAC2A, MIL7, SOC1, SOC2A, SOC2B, SOC4, SOC5, SOC6, SOC8, SOC9, SOC10, SOC11 e SOC12B.

Na Tabela 4 foram considerados os mesmos itens das Tabelas 1 e 5 para as cinco primeiras categorias, menos os seguintes: DEM2, AUT1, SOC1, SOC2A, SOC2B, SOC4, SOC6, SOC8 e SOC10; e para tolerância, os mesmos itens considerados nas Tabelas 3 e 7. 


\section{RESUMO}

A Psicologia Politica das Classes Sociais no Brasil: Atributos das Atitudes Políticas por Estratificação e Mobilidade Social

Neste artigo são testadas diferentes hipóteses derivadas da literatura especializada nacional e internacional sobre o efeito da estratificação e mobilidade social nas atitudes políticas e seus atributos no Brasil. São usados dados do Barômetro das Américas, rodada de 2012, pesquisa de opinião pública domiciliar com amostra representativa da população brasileira. Ao articular a literatura sobre classes sociais com a de psicologia política, o artigo interlaça duas vertentes teóricas que raramente dialogam para melhor especificar a potencial diferenciação comportamental por classes sociais e por padrões de mobilidade social. Assim, enfocamos variações tanto no conteúdo substantivo das opiniões de distintas classes, como também exploramos as distinções nos atributos das atitudes como não opinião, extremismo e heterogeneidade. Os achados demonstram um certo exagero da literatura brasileira atual em diferenciar a nova classe média das demais.

Palavras-chave: classe social; mobilidade social; atitudes políticas; psicologia política; tolerância

\section{ABSTRACT}

The Political Psychology of Social Classes in Brazil: Attributes of Political Attitudes by Stratification and Social Mobility

This article tests different hypothesis derived from the national and international specialized literature regarding the effect of stratification and social mobility in political attitudes and its attributes in Brazil. Data from the Barometer of the Americas (2012 round) was employed. The Barometer is a household survey with a representative sample of the Brazilian population. By articulating the literature on social classes with political psychology, the article interweaves two theoretical strands that rarely communicate to specify the potential behavior differentiation according to social classes and social mobility. Thus we focus on the substantial content of distinct classes, as we also explore the distinctions of the attributes of attitudes such as non-opinion, extremism and heterogeneity. The findings indicate a certain exaggeration of the current Brazilian literature in differentiating the middle class from the others.

Keywords: social class; social mobility; political attitudes; political psychology; tolerance 


\section{RÉSUMÉ}

La Psychologie Politique des Classes Sociales au Brésil: Les Attributs des Comportements Politiques en Fonction de la Stratification et de la Mobilité Sociales

Dans cet article, nous mettrons à l'épreuve différentes hypothèses issues de la littérature spécialisée, nationale et internationale, quant aux effets de la stratification et de la mobilité sociales sur les comportements politiques et leurs attributs au Brésil. Nous avons utilisé des données du Baromètre des Amériques de 2012, une enquête d'opinion publique à domicile à partir d'un échantillon représentatif de la population brésilienne. En mettant en parallèle la littérature sur les classes sociales avec celle de la psychologie politique, l'article entrelace deux courants théoriques au dialogue rare afin de mieux spécifier la différentiation comportementale potentielle par classes sociales et par modèles de mobilité sociale. Nous avons ainsi porté une attention particulière aussi bien aux variations du contenu substantif des opinions des différentes classes qu'aux distinctions dans les attributs des comportements, tels que l'absence d'opinion, l'extrémisme et l'hétérogénéité. Nos conclusions ont montré une certaine exagération de la littérature brésilienne actuelle dans la différentiation opérée entre la nouvelle classe moyenne et les autres.

Mots-clés: classe sociale; mobilité sociale; attitudes politiques; psychologie politique; tolérance

\section{RESUMEN}

La Psicología Politica de las Clases Sociales en Brasil: Atributos de las Actitudes Politicas por Estratificación y Movilidad Social

Este artículo examina diferentes hipótesis derivadas de la literatura especializada, nacional e internacional, sobre el efecto de la estratificación y de la movilidad social en las actitudes políticas y sus atributos en Brasil. Se han utilizado datos del Barómetro de las Américas de 2012, a partir de base de opinión pública domiciliar con una muestra representativa de la población brasileña. Al articular la discusión sobre clases sociales con el debate de la psicología política, el artículo vincula dos vertientes teóricas que no suelen dialogar, contribuyendo a explicar de forma más precisa la potencial diferenciación comportamental por clases sociales y por patrones de movilidad social. De este modo, atención especial es dada a las variaciones en el contenido sustantivo de las opiniones de las distintas clases y se analizan las distinciones en los atributos de las actitudes como no opinión, extremismo y heterogeneidad. Los hallazgos demuestran una cierta exageración de la literatura brasileña contemporánea en distinguir la nueva clase media de las demás.

Palabras clave: clase social; movilidad social; actitudes políticas; psicología política; tolerancia 